\title{
Transcriação e hiperfidelidade
}

Thelma Médici Nóbrega

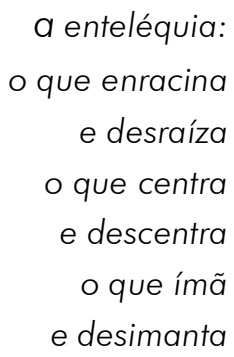

(Opúsculo Goetheano, Haroldo de Campos).

A transcriação é um conceito de difícil definição. $\bigcirc$ próprio Haroldo de Campos, ao longo do tempo, usou-o em diferentes acepções, para não falar dos muitos outros neologismos que cunhou para se referir às suas traduções de obras magnas da literatura mundial - como transparadização, no caso de Dante, transluciferação, no de Goethe. Por isso essa obra tradutória tão vária, que mantinha com a criação uma diferença de graus, e não de essência, pode ser vista por vários prismas, entre eles o da síntese extremamente pessoal entre seus principais inspiradores no plano literário, Pound e Mallarmé. 
Pound é o nome mais óbvio quando se fala de Haroldo e de seu irmão, Augusto. $\bigcirc$ processo tradutório de ambos está indissociavelmente ligado ao make it new poundiano. De modo geral, o termo "transcriação", como transformação do original, costuma ser confundido com "tradução livre", adaptação ou paráfrase, a invenção de um poema a partir de outro. $\bigcirc$ conceito também evoca a modernização do poema original por meio de linguagem atual, enxertos de versos contemporâneos extraídos de outros poemas ou canções. É a mesma visão que se tem do make it new poundiano, como criatividade ampla do tradutor, que usurpa a obra para o seu tempo e lugar, afastando-se da literalidade.

Uma parcela da obra tradutória de Haroldo parece ir nessa direção - a esse tipo de produção textual, ele dava o nome de "transluminuras", "algumas delas marcadamente parafrásicas", segundo ele.' Seriam poemas "mais propriamente 'reimaginados' do que "transcriados'". ${ }^{2}$ Um exemplo seria a ode de Horacio, "persicos odi, puer, apparatus", inclusa na seção "greguerias e latinórios" de Crisantempo, em que a singeleza boêmia do poeta latino é revivida por Haroldo via Noel Rosa: ${ }^{3}$

Garçom, faça o favor,

nada de luxos persas.

Nem me venha com estes

enfeites de tília.

Rosas? Não quero rosas,

se alguma ainda esquiva

Resta da primavera.

Mas a transcriação, para Haroldo, significava acima de tudo uma postura de fidelidade, ou de hiperfidelidade, como ele dizia: uma tradução atenta ao modo de construção do poema, a seus 
aspectos fono-semânticos, à sua configuração sígnica. Ou seja, uma literalidade e uma aderência ao signo. Uma abordagem oposta à tradução fiel ao conteúdo e à forma mais superficial do original (métrica e rima). Segundo ele, é esse o território por excelência da transcriação: o plano lingüístico, a "estrutura intratextual", o intracódigo.

Haroldo, sem dúvida, é herdeiro do legado de Pound, que, em sua poética sincrônica, buscou traduzir os clássicos de uma perspectiva moderna, resgatando-os do ponto de vista do presente de criação. Ele resume a arte tradutória de Pound em "Tradução tradição": "economia, concentração ao máximo do texto português em equivalência ao original, rejeições dos modos de dizer que alonguem em demasia o verso traduzido, adoção de formas correntias de linguagem apanhada viva, respeito à empostação do segmento de poema considerado". ${ }^{4}$ Em Pound, portanto, estaria a modernização, a aproximação do contexto do tradutor, a apropriação que abala a primazia do original em proveito da eficácia estética da tradução na língua de chegada. ${ }^{5}$

Mas Haroldo estava igualmente próximo de Mallarmé, que Pound não incluiu em seu paideuma. De fato, todo o seu programa poético, que resultou nos movimentos imagista e depois vorticista, foi uma reação à poesia pós-simbolista anglo-americana, uma tentativa de reformá-la. ${ }^{6}$ Haroldo e os outros poetas concretos, no entanto, desde o início viram compatibilidades entre a poesia de Pound e a de Mallarmé. Perceberam, com razão, que ambos os escritores pertenciam à mesma linhagem pós-romântica, na contramão do classicismo.

Haroldo relacionou o método ideogrâmico, que Pound extraiu de Fenollosa, ao Coup de dés, poema cósmico-visual de Mallarmé. Em traduções de haicais de Bashô e Li-Tai-Po, publicadas em 1958, bem como em sua coletânea de poemas chineses, à diferença do método de Pound, mais "imagista", ele adotou um foco etimológico, procurando forçar a língua portuguesa a imitar 
a estrutura morfossintática do original, ao passo que Pound não era favorável à importação de estruturas sintáticas do idioma estrangeiro. ${ }^{7}$ Um exemplo é o verso de uma ode confuciana, que Pound traduziu de modo linear como "Lady of azure thought, supple and tall", e Haroldo verteu parataticamente como "moça bela/ azul-serena/polpa de cedro", levando em conta a etimologia visual dos ideogramas.

Haroldo radicaliza o método ideogrâmico, aproximando-o da paixão etimológica de Mallarmé e dos precursores deste, os românticos alemães, sobretudo o poeta-tradutor Hölderlin, que levou ao extremo a transformação do alemão sob o impacto da morfologia e da sintaxe do grego. Haroldo era herdeiro dessa tradição, também vinculada à hermenêutica cabalista, de fidelidade à letra do original. Um dos melhores lugares para observar essa estratégia é a tradução que Haroldo fez do próprio Coup de Dés. São vários os momentos em que ele realiza uma aproximação etimológica na tradução, uma literalidade radical.

Ao propor "pensa" para "penché", ele parte do latin pendere, (pender, ponderar, pesar), que está na raiz do verbo francês pencher, causando em português uma ambigüidade entre o adjetivo "pensa" e o verbo "pensar". "Le vieillard vers cette" ficou "o velho versus esta", já que versus, no sentido latino, significa "em direção $a^{\prime \prime}$, recuperando a ambigüidade do francês vers, que vem do latim versus (linha escrita, verso). Outro exemplo é "êxito", próximo do latim exitus, para "issu" (saída). Em "apartado" para "écarté", comparece um intertexto camoniano ("Já no alto oceano navegavam,/as inquietas ondas apartando"). ${ }^{8}$ Nessa fidelidade radical, a etimologia diacrônica se transforma em etimologia sincrônica, poética, abalando tanto a língua do original como a língua da tradução e incorporando elementos intertextuais que aproximam o original do contexto luso-brasileiro.

Ao longo de sua trajetória, Haroldo continua a usar essa tática de aproximação e afastamento, de chegar à raiz da palavra 
para depois desenraizá-la, de buscar o centro para depois deslocálo. Outro exemplo seria a tradução do Qohélet, ou Eclesiastes, em que a hebraização do português se combina à utilização de recursos prosódicos de autores brasileiros como Guimarães Rosa, João Cabral de Melo Neto e Caetano Veloso.

Sobre essas traduções, Haroldo poderia dizer, como disse a respeito da tradução que Augusto de Campos fez dos Rubáyát de Omar Khayyám traduzidos por Edward Fitzgerald: "Fica evidente que aqui houve não apenas uma transcriação do texto, mas uma recriação do extratexto (do qual fazem parte tanto o referente contextual quando o intertexto citacional). Make it new". 9 Para Haroldo, portanto, o emblema poundiano significava que a transcriação do texto, visando à literalidade, deveria levar à transformação criativa do extratexto - à modernização do contexto histórico, muitas vezes através da incorporação de intertextos que aproximam a tradução do presente de criação. Assim, passado e presente, literalidade e criatividade, nacional e estrangeiro não se excluem mas mantém uma relação dialética e vital.

Pode-se dizer que essa síntese, essa combinação de contrários, é a contribuição original de Haroldo à teoria e à prática da tradução. A tensão entre esses pólos garante a força e a vitalidade de suas traduções. Assim, o conceito de transcriação suspende e desloca a dicotomia fidelidade/criatividade. Paradoxalmente, é o excesso de fidelidade, a desmesura mimetizante, que leva à transformação do original. Na tentativa de reproduzir o desenho fonosemântico da língua do original, seu perfil morfo-sintático,o poeta-tradutor acaba instaurando a novidade ao nível intratextual mas também extratextual, da historicidade do texto. Portanto, não é descabido dizer que "hiperfidelidade" é outro nome para a "transcriação".

É claro que existe aí uma busca utópica, um desejo de não abrir mão de nada. Derrida detectou esse desejo quando escreveu sobre a escritura de Haroldo: "Quer dizer que serão preciso 
séculos para medir o que este século deve a essa obra única: fonte única por assinalar um corpus poético e teórico original que no entanto fecunda, tirando a cada volta de uma língua outra, uma espécie de tradução inflexível e adoradora, generadora e generosa, quer dizer que a si mesma extravasa, (...) para não renunciar a nada (não renunciar a nada é o gênio do inconsciente e o inconsciente do gênio, a fonte libidinal única de todo pensamento poético), a um só tempo do lado da mundialidade e no entanto do lado da mais irredutível singularidade do idioma". ${ }^{10}$

Derrida compreendeu a duplicidade paradoxal da prática tradutora de Haroldo, entre o pólo do universal e do nacional, do mesmo e do estrangeiro, da distância e da proximidade em relação ao original. E que o desejo de absoluto, de não renunciar a nada, é a essência da poesia. E da filosofia, iá que Derrida não as separa. Não renunciar a nada - era essa também a divisa de Mallarmé, que, nas notas à sua tradução de Les Dieux Antiques, alude a esse anseio, ao oscilar entre a vontade de manter os nomes dos deuses no original, para que não se desfizessem "em água, luz ou vento elementares", e a necessidade de transformálos. No entanto, entre a conservação do original no grego ou no latim e sua transformação, segundo o gênio da língua francesa, ele prefere ficar com os dois: "Não renunciemos a nenhuma dessas duas felicidades". ${ }^{11}$

SOBRE A AUTORA

Thelma Médici Nóbrega é professora do curso de Tradutor do UNIVEM, tradutora e doutora pelo Programa de Comunicação e Semiótica da PUC/SP. Sua tese de doutorado é a biografia literária de Haroldo de Campos. 
Cadernos de Literatura em Tradução, n. 7, p. 249-255

\section{NOTAS}

1 Cf."Epifanias poéticas", revista Cult, agosto de 1998.

2 Em Crisantempo: no espaço curvo nasce um. São Paulo: Perspectiva, 1998, p. 359.

3 Em Sobre Finismundo: a última viagem. Rio de Janeiro: Sette Letras, 1996, p. 25.

4 Em Ezra Pound: antologia poética. São Paulo/Brasília: Hucitec/UnB, 1985, p. 209.

5 Mas, mesmo para Pound, o make it new não significava apenas isso. Para modernizar um original, ele podia tanto usar um idioma poético mais arcaico, como na sua tradução de The Seafarer, como mais moderno, caso das traduções reunidas em Cathay. A respeito, ver John Milton, Tradução: teoria e prática. São Paulo: Martins Fontes, 1998, p. 106.

6 Cf. Hugh Kenner, The Pound Era. University of California Press, 1997, p. 183.

7 Cf. John Milton, op. cit, p. 119.

8 Cf. Haroldo de Campos, "Preliminares a uma tradução do Coup de Dés de Stéphane Mallarmé", em Mallarmé. São Paulo: Perspectiva, 1975, p. 119-147.

9 Cf. Haroldo de Campos, "Tradução, ideologia e história", em Território da Tradução. Campinas: IEL, 1984, p. 245.

10 Em Jacques Derrida, "Cada vez, quer dizer, e no entanto, Haroldo", trad. Leda Tenório da Motta, Homenagem a Haroldo de Campos, PUC-SP, 1996, p. 13.

11 Cf. Stéphane Mallarmé. Oeuvres Complètes. Paris: Gallimard, 1945, p. 1277. 